\title{
Electrical and magnetic properties of $\mathrm{RPt}_{2} \mathrm{In}_{2}$ $(\mathrm{R}=\mathrm{La}, \mathrm{Ce}, \mathrm{Pr}, \mathrm{Nd}$, and $\mathrm{Gd})$ systems
}

\author{
J.W. Chen*, B.K. Wang \\ Department of Physics, National Taiwan University, Taipei, Taiwan, ROC
}

\begin{abstract}
We have investigated the transport and magnetic properties of $\mathrm{RPt}_{2} \mathrm{In}_{2}(\mathrm{R}=\mathrm{La}, \mathrm{Ce}, \mathrm{Pr}, \mathrm{Nd}$, and Gd) compounds by means of the $\mathrm{AC}$ electrical resistivity $\rho$ and DC magnetic susceptibility $\chi$ measurements. Both $\rho(T)$ and $\chi(T)$ data indicate that $\mathrm{LaPt}_{2} \mathrm{In}_{2}$ and $\mathrm{PrPt}_{2} \mathrm{In}_{2}$ are non-magnetic above $2 \mathrm{~K}$. The $\rho(T)$ curve for $\mathrm{CePt}_{2} \mathrm{In}_{2}$ reveals characteristics of a Kondo system with a minimum occurs at $16 \mathrm{~K}$ and a logarithmic increase in $\rho(T)$ at lower temperature. The occurrence of a peak in the $\chi(T)$ curve indicates that $\mathrm{NdPt}_{2} \mathrm{In}_{2}$ undergoes antiferromagnetic transition with $T_{\mathrm{N}}=3.52 \mathrm{~K}$. Two magnetic transitions were observed in $\mathrm{GdPt}_{2} \mathrm{In}_{2}$ with transition temperatures of $\sim 50 \mathrm{~K}$ and $16 \mathrm{~K}$, respectively.

(C) 2006 Elsevier B.V. All rights reserved.
\end{abstract}

Keywords: Kondo system; Magnetic properties

\section{Introduction}

During the past few decades there have been a lot of research activities on the ternary intermetallic compounds because of their interesting properties such as magnetic superconductors and heavy electron systems $[1,2]$. Recently, it was reported that $\mathrm{RPt}_{2} \mathrm{In}_{2}(\mathrm{R}=\mathrm{La}, \mathrm{Ce}, \mathrm{Pr}$, and $\mathrm{Nd}$ ) compounds crystallize in monoclinic $\mathrm{CePt}_{2} \mathrm{In}_{2}$-type structure [3]. To the best of our knowledge, the physical properties of these compounds have not been studied yet till now. In this report, we present our results of the AC electrical resistivity and DC magnetization studies on the $\mathrm{RPt}_{2} \mathrm{In}_{2}(\mathrm{R}=\mathrm{La}, \mathrm{Ce}, \mathrm{Pr}, \mathrm{Nd}$, and $\mathrm{Gd})$ systems.

\section{Experimental details}

The polycrystalline samples of $\mathrm{RPt}_{2} \mathrm{In}_{2}(\mathrm{R}=\mathrm{La}, \mathrm{Ce}, \mathrm{Pr}$, $\mathrm{Nd}$, and $\mathrm{Gd}$ ) were prepared by arc-melting the high-purity elements (R elements: 99.99\%, Pt: 99.99\%, In: 99.999\%) together in a water-cooled copper hearth in a $\mathrm{Zr}$-gettered argon atmosphere. To improve the sample homogeneity, the as-melted samples were subsequently annealed in argon

\footnotetext{
*Corresponding author. Tel.: + 886233665172 ; fax: + 88623639984 .

E-mail address: jwchen@phys.ntu.edu.tw (J.W. Chen).
}

atmosphere at $600{ }^{\circ} \mathrm{C}$ for 4 weeks. Powder X-ray diffraction patterns reveal that the samples prepared are of the $\mathrm{CePt}_{2} \mathrm{In}_{2}$-type structure for $\mathrm{R}=\mathrm{La}, \mathrm{Ce}, \mathrm{Pr}$ and $\mathrm{Nd}$, with the lattice constants close to that of the reported values [3]. AC electrical resistivity of bar-shaped samples has been measured between 4.2 and $300 \mathrm{~K}$ in a $\mathrm{He}^{4}$ cryostat using a four-probe $\mathrm{AC}$ technique. DC magnetic susceptibility measurements were performed in a commercial superconducting quantum interference device (SQUID) magnetometer from 2 to $300 \mathrm{~K}$ in an applied field of $5000 \mathrm{Oe}$.

\section{Results and discussion}

The normalized electrical resistance $R(T) / R(300 \mathrm{~K})$ vs. $T$ curves for the $\mathrm{RPt}_{2} \mathrm{In}_{2}(\mathrm{R}=\mathrm{La}, \mathrm{Ce}, \mathrm{Pr}, \mathrm{Nd}$, and $\mathrm{Gd})$ compounds are plotted in Fig. 1 for $0 \mathrm{~K} \leqslant T \leqslant 300 \mathrm{~K}$. The $R(T) / R(300 \mathrm{~K})$ curves for these samples exhibit typical characteristics of common metal and decrease monotonically with decreasing temperature $T$. In addition, a rapid drop in the $\rho(T)$ curve is observed at $T=14 \mathrm{~K}$ for $\mathrm{GdPt}_{2} \mathrm{In}_{2}$, indicating the occurrence of magnetic ordering in this compound. This is shown in the inset of figure, where $\rho(T)$ curves for $\mathrm{CePt}_{2} \mathrm{In}_{2}$ and $\mathrm{GdPt}_{2} \mathrm{In}_{2}$ are plotted for $T \leqslant 30 \mathrm{~K}$. For $\mathrm{CePt}_{2} \mathrm{In}_{2}$, the $\rho(T)$ curve reveals characteristic of a Kondo system with a minimum occurs at 


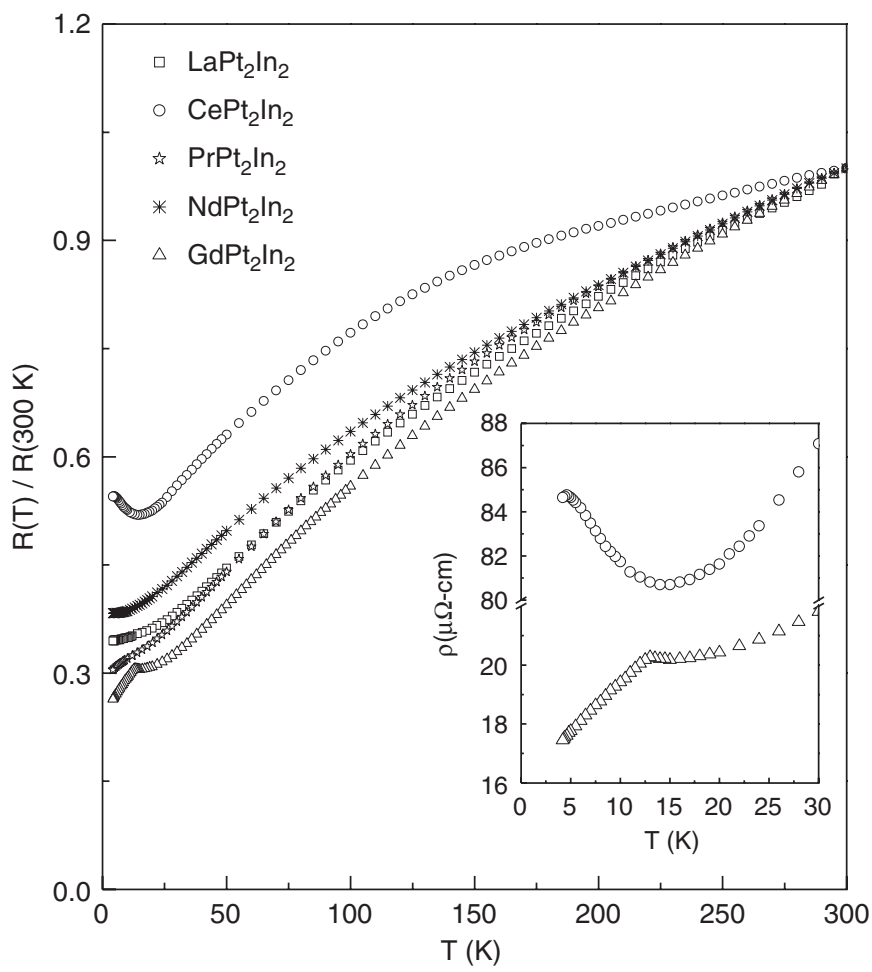

Fig. 1. $R(T) / R(300 \mathrm{~K})$ for $\mathrm{RPt}_{2} \mathrm{In}_{2}(\mathrm{R}=\mathrm{La}, \mathrm{Ce}, \mathrm{Pr}, \mathrm{Nd}$, and $\mathrm{Gd})$. The inset depicts the $\rho(T)$ curves for $\mathrm{CePt}_{2} \mathrm{In}_{2}$ and $\mathrm{GdPt}_{2} \mathrm{In}_{2}$ for $T<30 \mathrm{~K}$.

$16 \mathrm{~K}$ and a logarithmic increase in $\rho(T)$ below that temperature. The occurrence of a maximum in the $\rho(T)$ curve at $\sim 4.6 \mathrm{~K}$ and saturation of the $\chi(T)$ at low temperature (Fig. 2) confirm that $\mathrm{CePt}_{2} \mathrm{In}_{2}$ is a Kondo lattice.

Fig. 2 shows the inverse susceptibility $\chi^{-1}$ as a function of temperature $T$ for $\mathrm{RPt}_{2} \mathrm{In}_{2}(\mathrm{R}=\mathrm{Ce}, \mathrm{Pr}, \mathrm{Nd}$, and $\mathrm{Gd})$ measured in an applied field $H=5 \mathrm{kOe}$ for $0 \mathrm{~K} \leqslant T \leqslant$ $300 \mathrm{~K}$. The magnetic susceptibility data reveal that both $\mathrm{CePt}_{2} \mathrm{In}_{2}$ and $\mathrm{PrPt}_{2} \mathrm{In}_{2}$ are nonmagnetic down to $2 \mathrm{~K}$. While for $T>100 \mathrm{~K}, \chi$ follows a Curie-Weiss behavior $\chi=C /\left(T-\Theta_{\mathrm{p}}\right)$, with $\Theta_{\mathrm{p}}=-16.7$ and $-40.2 \mathrm{~K}$ for $\mathrm{CePt}_{2} \mathrm{In}_{2}$ and $\mathrm{PrPt}_{2} \mathrm{In}_{2}$, respectively. The effective moment $\mu_{\text {eff }}$ obtained from the Curie constant $C=N \mu_{\mathrm{eff}}^{2} / 3 k_{\mathrm{B}}$ are $\mu_{\text {eff }}=2.51 \mu_{\mathrm{B}}$ per Ce ion and $\mu_{\text {eff }}=3.52 \mu_{\mathrm{B}}$ per Pr ion. The obtained values are close to the values of the moments for the $\mathrm{Ce}^{3+}\left(\mu_{\text {eff }}=2.54 \mu_{\mathrm{B}}\right)$ and $\operatorname{Pr}^{3+}\left(\mu_{\mathrm{eff}}=3.58 \mu_{\mathrm{B}}\right)$ ions.

The magnetic susceptibility curve for $\mathrm{NdPt}_{2} \mathrm{In}_{2}$ exhibits a peak at $T=3.52 \mathrm{~K}$, which indicates the occurrence of antiferromagnetic transition in this compound. The $\chi(T)$ curve can also be described with Curie-Weiss law for $T>100 \mathrm{~K}$ with $\mu_{\mathrm{eff}}=3.57 \mu_{\mathrm{B}}$ and a Curie-Weiss paramagnetic intercept $\Theta_{\mathrm{p}}=-17.6 \mathrm{~K}$.

The $\chi(T)$ curve reveals two magnetic transitions for $\mathrm{GdPt}_{2} \mathrm{In}_{2}$. This is shown in the inset of Fig. 2, where $\chi(T)$ curves for $\mathrm{NdPt}_{2} \mathrm{In}_{2}$ and $\mathrm{GdPt}_{2} \mathrm{In}_{2}$ are plotted for $0 \mathrm{~K} \leqslant T$ $\leqslant 100 \mathrm{~K}$. A rapid increase of $\chi(T)$ value at $\sim 50 \mathrm{~K}$ to a maximum at $T \sim 20 \mathrm{~K}$, together with a positive value of $\Theta_{\mathrm{p}}=25.5 \mathrm{~K}$ reveal the occurrence of a ferromagnetic-type

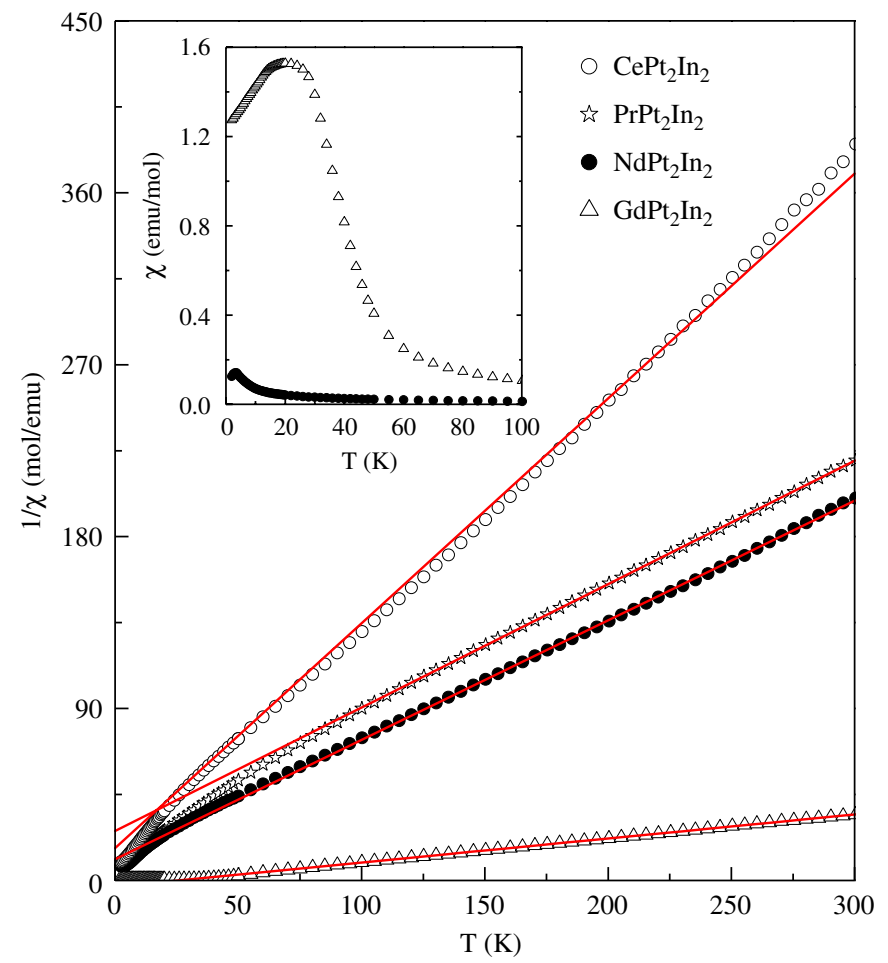

Fig. 2. $1 / \chi$ vs. $T$ for $\mathrm{RPt}_{2} \mathrm{In}_{2}(\mathrm{R}=\mathrm{Ce}, \mathrm{Pr}, \mathrm{Nd}$, and $\mathrm{Gd})$ with the solid lines represent the $\mathrm{CW}$ fit for the samples. The inset shows the $\chi(T)$ behavior of the $\mathrm{NdPt}_{2} \mathrm{In}_{2}$ and $\mathrm{GdPt}_{2} \mathrm{In}_{2}$ compounds.

transition at $T \sim 50 \mathrm{~K}$. In addition, the occurrence of a linear decrease of the $\chi(T)$ at $T=16 \mathrm{~K}$, near the temperature that a rapid drop in the $\rho(T)$ curve is observed for this compound, indicates that antiferromagnetic-type ordering occurs at lower temperature for $\mathrm{GdPt}_{2} \mathrm{In}_{2}$.

In summary, we have studied the electrical and magnetic properties of $\mathrm{RPt}_{2} \mathrm{In}_{2}(\mathrm{R}=\mathrm{La}, \mathrm{Ce}, \mathrm{Pr}, \mathrm{Nd}$, and $\mathrm{Gd})$ compounds. Both $\rho(T)$ and $\chi(T)$ data indicate that $\mathrm{LaPt}_{2} \mathrm{In}_{2}$ and $\mathrm{PrPt}_{2} \mathrm{In}_{2}$ are non-magnetic above $2 \mathrm{~K}$. $\mathrm{CePt}_{2} \mathrm{In}_{2}$ is a Kondo lattice as inferred from $\rho(T)$ and $\chi(T)$ data. The occurrence of a peak in the $\chi(T)$ curves indicates that antiferromagnetic transition occurs in $\mathrm{NdPt}_{2} \mathrm{In}_{2}$ at $3.52 \mathrm{~K}$. Two magnetic transitions were observed in $\mathrm{GdPt}_{2} \mathrm{In}_{2}$ with transition temperatures of $\sim 50 \mathrm{~K}$ and $16 \mathrm{~K}$, respectively.

\section{Acknowledgment}

This work was supported by the ROC National Science Council under Grant no. NSC 93-2112-M-002-038.

\section{References}

[1] Ø. Fischer, M.B. Maple (Eds.), Superconductivity in Ternary Compounds, vols. I \& II, Springer, New York, 1982.

[2] G.R. Stewart, Rev. Mod. Phys. 56 (1984) 755.

[3] V. Zaremba, Ya. Galazhun, Ya. Kalychak, D. Kaczorowski, J. Stepien-Damm, J. Alloys Compounds 296 (2000) 280. 